brous scar formation in experimental animal eyes. Arch Ophthalmolol. 2009; 127: 460-464.

36. Wolner B., Liebmann J. M., Sassani J. W. et al. Late blebrelated endophthalmitis after trabeculectomy with adjunc- tive 5-fluorouracil // Ophthalmology. - 1991. - Vol. 98, № 7. - P. 1053-1060.

Поступила 12.10.2011

Рецензент к. М. Н. А. В. Артемов

\title{
PECULIARITIES OF REPARATION OF THE OUTFLOW TRACTS IN SINUSOTRABECULOTOMY WITH THE APPLICATION OF VISCOELASTIC ACCORDING TO THE DATA OF LIGHT AND ELECTRON MICROSCOPY
}

Bobrova N. F., Vit V. V., Dumbrova N. E., Molchanyuk N. I., Sorochinskaya T. A., Trofimova N. B. Odessa, Ukraine

The regeneration process of the outflow tracts of the intraocular fluid after sinusotrabeculotomy with the application of viscoelastic containing the hyaluronic acid and without it was studied in the experiment with 15 rabbits (28 eyes).

The histological and electron-microscopic studies showed that the application of viscoelastic from the derivatives of the hyaluronic acid as fluid implant allows to form the outflow tracts of the intraocular fluid at the expense of reduction of the scarring processes in the area of sinusotrabeculotomy. The process of substituting regeneration of the sclera is slowed down in introduction of viscoelastic (Viscoat) in the anterior chamber and between the scleral grafts.

At the same time in control eyes (without application of viscoelastic) the signs of inflammation and substitutive regeneration are manifested already in 10 days after the operation and complete obliteration of the wound canal is revealed in a month.

УДК 617.713-002-02:616.833.15-092.9

\section{МОДЕЛЬ НЕЙРОТРОФИЧЕСКОГО КЕРАТИТА (КЕРАТОПАТИИ)}

Г. И. Дрожжина, д-р. мед. наук, О. Н. Иванова, канд. мед. наук., Т. Б. Гайдамака, д-р. мед. наук, В. В. Вит, проф.

гУ «Институт глазных болезней и тканевой терапии им. В. П. Филатова НАМН Украины, Одесса

\begin{abstract}
Мета дослідження: розробити модель нейротрофічного кератиту в експерименті іn vivo, максимально наближену до клінічних умов прояву нейротрофічного процесу в рогівці.

Результати: у експерименті на 10 кроликах (20 очей) відтворена модель нейротрофічного кератиту максимально наближена до клінічних умов. Завдяки поєднанню чинників порушення іннервації і живлення зони лімба (передавлювання силіконовим ииркляжем задніх цілиарних нервів і артерій), дефекту тканини (стромэктомія) рогівки і гальмування регенерації (інстиляції кортикостероїдів в кон'юнктивальну порожнину), в рогівці дослідних тварин розвивався нейротрофічний кератит.
\end{abstract}

Ключевые слова: роговая оболочка, нейротрофический кератит, экспериментальная модель

Ключові слова: рогова оболонка, нейротрофічний кератит, експериментальна модель

Введение. Одним из факторов физиологической регенерации роговицы является взаимодействие чувствительной, симпатической и парасимпатической иннервации. При нарушении этого взаимодействия возникает снижение чувствительности роговицы, уменьшение слезопродукции, что ведет к нарушению регенерации поверхности роговицы и развитию нейротрофического процесса в тканях роговой оболочки $[1,3,7,9,13,14,17]$.

В 2003 г. на Кембриджском офтальмологическом симпозиуме было сформулировано определение нейротрофической кератопатии как дегенеративного заболевания роговицы, индуцируемого поражением тройничного нерва (V пара черепномозговых нервов), которое приводит к снижению или потере чувствительности роговицы, уменьшению слезопродукции, и как следствие - нарушению регенерации роговицы [13]. Известно, что поражение пятой пары черепно-мозговых нервов, может происходить на разных уровнях (в ядре, гассеровом узле, на уровне глазной ветви тройничного нерва, назоцилиарного или длинных цилиарных нервов) и проявляется при различных заболеваниях

(с) Г. И. Дрожжина, О. Н. Иванова, Т. Б. Гайдамака, В. В. Вит, 2011 
поверхности глаза, системных заболеваний организма, а также после хирургических вмешательств $[8,9,10,12,15,18,21]$.

Наиболее частыми причинами снижения чувствительности роговицы являются вирусные инфекции (герпес Simplex и герпес Zoster), хронические повреждения или воспалительные заболевания поверхности глаза, ношение контактных линз, наследственные дистрофии роговицы, последствия химических ожогов, травм, парезы V пары черепно-мозговых нервов, в том числе после удаления неврином слухового нерва, менингиом и аневризм, хирургические операции на роговице (фоторефракционная кератэктомия, LASIK, кератопластика и др.) и на глазу (после хирургических и лазерных вмешательств, витрэктомии (травма или сдавливание цилиарных нервов), и проч. Нарушение чувствительности роговицы наблюдается при некоторых системных заболеваниях (при сахарном диабете, рассеянном склерозе, лепре, недостаточности витамина А и др.), а также в результате токсического влияния некоторых лекарственных препаратов - местного применения анестетиков, тимолола, нестероидных противовоспалительных препаратов, дексаметазона и др. [10, 13, 19, 21, 23, 24]. А. А. Юмашева, исследовав динамику морфологических и биометрических изменений глаза при циркляже, показала, что одним из осложнений циркляжа глазного яблока является нарушение чувствительности роговицы, перилимбальная васкуляризация, помутнение роговицы, эффект Тиндаля в передней камере. Перечисленные изменения роговицы автор связывала, главным образом, с передавливанием задних цилиарных нервов. Ею доказано, что с увеличением затягивания циркляжного материала степень выраженности трофических изменений в роговичной ткани увеличивается [12].

Согласно классификации Ү. А. Makie (1995 г.), в клиническом течении нейротрофической кератопатии выделено три стадии. Первая стадия характеризуется точечной кератопатией, гиперплазией эпителия и его иррегулярностью, поверхностной неоваскуляризацией и образованием помутнения в строме. Вторая стадия характеризуется наличием персистирующих дефектов эпителия (ПДЭ), отеком стромы, складками десцеметовой мембраны, возможна воспалительная реакция во влаге передней камеры, иногда с наличием стерильного гипопиона. Для третьей стадии характерно вовлечение в патологический процесс стромы с формированием язвы роговицы, которая может осложниться расплавлением стромы, перфорацией и вести к потере зрения и глаза [20].

Лечение нейротрофической кератопатии (кератита) является одним из самых сложных в офтальмологии. Сложности лечения этой патологии роговицы связаны с разнообразными этиологическими факторами, особенностями патогенеза и клинических проявлений заболевания, долговременной терапией, а также развитием тяжелых осложнений. $[8,10,14,15]$. Поэтому создание моделей нейротрофической кератопатии с целью совершенствования существующих и разработки новых методов лечения этой тяжелой патологии роговицы является актуальной проблемой офтальмологии.

Для изучения регенерации ткани роговицы и оптимизации методов лечения нейротрофического кератита были предложены разные экспериментальные модели. В частности: В. С. Беляев (1984) применял кольцевидную электрокоагуляцию, однако изменения роговицы, лежащие в основе этой модели имели термическое постожоговое происхождение [1]; П. В. Макаров и соавт. (2002) проводили тотальную хирургическую резекцию лимбальной зоны, эта модель наиболее приближена к посттравматическому происхождению [9]; Е. С. Милюдин (2006) предложил экспериментальную модель недостаточности региональных стволовых клеток роговичного эпителия, включающую деэпителизацию роговицы $20 \%$ раствором этилового спирта с последующей аппликацией $0.04 \%$ митомицина С на область лимба, в результате развивалось химическое цитотоксическое поражение тканей роговицы [11]. Nakamura с соавт. в 2003 г. моделировал нейротрофический процесс в неонатальном периоде у крыс, путем подкожного введения однократной дозы капсаицина, вызывая токсическое воздействие на ткани роговицы [22]. Другим японским ученым Takashi Nagano в 2003 г. была произведена денервация роговицы экспериментальных животных путем термокоагуляции глазной ветви тройничного нерва [25]. В 2011 году Ferrari G. и соавт. предложили электростатический электролиз глазной веточки тройничного нерва у мышей [16]. Однако последние модели имеют ряд технических трудностей при воссоздании их в эксперименте.

Целью нашего исследования явилось разработать максимально приближенную к многокомпонентным клиническим проявлениям нейротрофического процесса в роговице экспериментальную модель нейротрофического кератита (кератопатии) in vivo.

МАТЕРИАЛ И МЕТОДЫ. Для моделирования нейротрофического кератита в условиях in vivo использовали 10 кроликов (20 глаз) породы шиншилла массой 2,0-3,5 кг. Экспериментальное исследование было одобрено биоэтическим комитетом ГУ «Института глазных болезней и тканевой терапии им. В. П. Филатова НАМН Украины». Моделирование нейротрофического кератита (кератопатии) проводили в виварии института [6]. Наблюдение, уход, оперативное вмешательство на животных, а также выведение их из эксперимента выполнялись в соответствии с международными правилами по работе с опытными животными (Хельсинская декларация об использовании животных в экспериментальных исследованиях 1964-2000гг.). 
После предварительного введения животного в наркоз, измеряли величину суммарной слезопродукции - проводили пробу Ширмера, которая у здоровых кроликов с интактной роговицей составляла 10-11мм. Тонометром Маклакова (7,5 г) измеряли внутриглазное давление, которое равнялось в среднем 16,5 мм рт. ст. Исходные данные внутриглазного давления, согласуясь с литературными источниками, были приняты нами за норму [5].

Конъюнктиву отсепаровывали по окружности от лимба. Выделяли наружные прямые мышцы, под которыми проводили силиконовую ленту шириной 4.5 мм, фиксировали ее эписклерально швами (шелк 5/0) и затягивали до повышения цифр офтальмотонуса на 3-4 мм рт. ст. (под контролем тонометрии грузиком 7,5 г). Трепаном ФМ-V диаметром 6.0 мм в центральной зоне роговицы делали насечку эпителия и поверхностных слоев роговицы глубиной на 1/3 толщины, затем с помощью круглого ножа и ножниц Кастровьехо производили стромэктомию. На конъюнктиву накладывали узловые швы (шелк 5/0). В конъюнктивальную полость закапывали раствор антисептика (30\% альбуцид). В послеоперационном периоде, начиная с первых суток эксперимента, проводили инстилляции раствора антисептика (30\% альбуцид) и кортикостероида (0,01\% раствор дексаметазона) в конъюнктивальную полость 3р. в день в течение всего эксперимента. Наблюдение за состоянием роговицы проводилось в динамике с помощью бокового фокального освещения, биомикроскопии с флюоресцеиновым тестом, фоторегистрации изменений роговицы. У всех животных до начала эксперимента и на 29 сутки проводили микробиологическое исследование. Во всех случаях посевы роста не дали.

РЕЗУЛЬТАТЫ И ИХ ОБСУЖДЕНИЕ. Через одни сутки от начала эксперимента при биомикроскопии переднего отдела глаза наблюдались светобоязнь, наличие скудного слизистого отделяемого в конъюнктивальной полости, окрашивание роговицы флюоресцеином в области стромэктомии и за ее пределами до 7 мм в диаметре. Окружающая ткань собственной роговицы оставалась прозрачной. На третьи сутки отмечали сохранение светобоязни, увеличение слизистого отделяемого, дефект роговицы в пределах стромэктомии ограничился, с окрашиванием флюоресцеином до 5,5 мм в диаметре, поверхность окружающей роговицы пропитывалась по типу эпителиопатии, с нежным разрежением ткани в слоях. Через 5 суток у экспериментальных животных сохранялась светобоязнь, снизилась слезопродукция - проба Ширмера составляла 6-7 мм, отмечалось умеренное количество слизистого нитеподобного отделяемого. В центре стромэктомии дефект поверхностных слоев роговой оболочки ограничился до 0,5-1,0 мм, на остальном протяжении пропитываясь флюоресцеином по типу эпителиопатии. Окружающая ткань роговицы оставалась прозрачной. На 7 сутки от начала эксперимента (рис. 1) проба Ширмера составляла 5,5-6,0 мм, вся поверхность роговицы кроликов заэпителизировалась. Однако поверхность эпителия была шероховатой, в нижнем отделе по ходу пограничного кольца стромэктомии точечно прокрашивалась флюоресцеином по типу эпителиопатии. К 14 суткам (рис.2) после завершения эпителизации дефекта поверхностных слоев стромы начали формироваться нейротрофические изменения, которые биомикроскопически выражались в виде: наличия слизистого нитчатого отделяемого в конъюнктивальной полости, точечной кератопатии, гиперплазии и иррегулярности эпителия, а также наличием поверхностной неоваскуляризации, что клинически соответствовало I стадии нейротрофической кератопатии по Mackie (1995). Наблюдалось снижение слезопродукции - проба Ширмера составляла 4,8-5,0 мм. Через 19 суток от начала эксперимента появлялись персистирующие дефекты эпителия роговицы с отеком стромы. К 29 суткам (рис. 3) - при биомикроскопии роговицы экспериментальных животных к ранее описанным трофическим изменениям присоединились помутнения стромы роговицы, нежные складки десцеметовой оболочки, эффект Тиндаля во влаге передней камеры, что клинически соответствовало II стадии нейротрофической кератопатии по Mackie (1995). На разработанную модель нейротрофического кератита подана заявка и получена приоритетная справка № 201106827 [6].

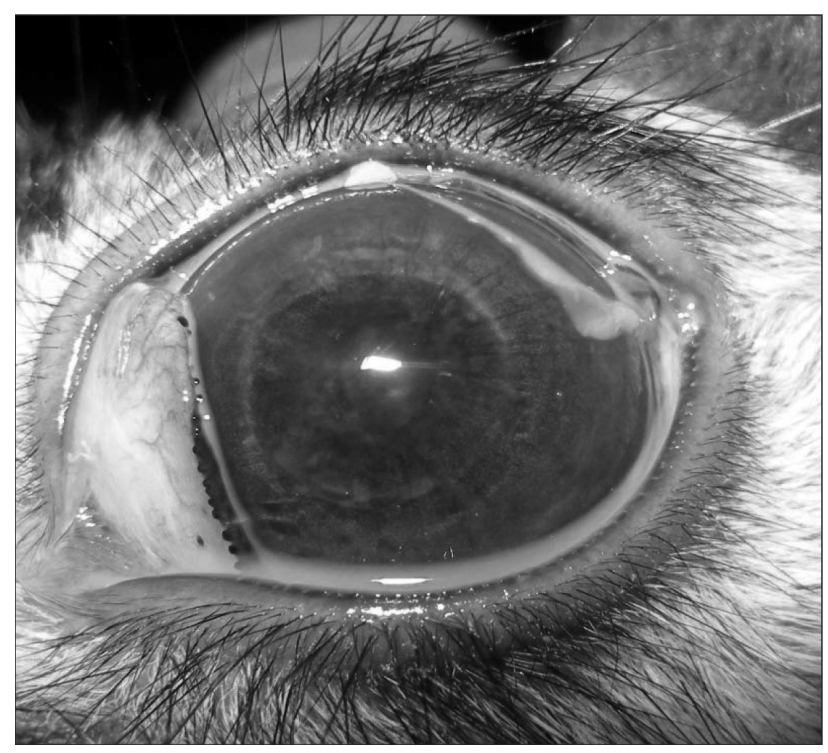

Рис. 1. Моделированный нейротрофический кератит, 7 сутки. Снижение слезопродукции, слизистое нитчатое отделяемого в конъюнктивальной полости, точечная кератопатия.

Развитие нейротрофического кератита в роговице экспериментальных животных на разработанной модели обусловлено комплексным воздействием на анатомические структуры (артерии и нервы) глазного яблока - передавливанием при наложении циркляжа задних цилиарных нервов, нарушением в результате стромэктомии субэпителиального нервного сплетения и торможением регенерации роговицы инстилляциями препарата кортикостероидов. Известно, что главным источником сенсорной иннервации роговицы являются длинные 
ресничные нервы, являющиеся глазной ветвью тройничного нерва. Проникая в склеру вблизи лимба, они образуют перикорнеальное сплетение, а проникая через отверстия в боуменовой оболочке, формируют подэпителиальное нервное сплетение. Доказано, что вегетативная иннервация роговицы обеспечивает ее трофику, осуществляясь из волокон тройничного, ресничного и верхне-шейного ганглиев [4]. Денервация роговой оболочки в эксперименте приводила к развитию дистрофического процесса, напоминающего нейропаралитический кератит у человека. Аналогичные трофические изменения роговицы наблюдались и после циркляжа силиконовой лентой и другими материалами [12]. В настоящее время установлено наличие двусторонних обменных связей между эпителием роговой оболочки и терминальными нервными окончаниями в области эпителия, вырабатывающими нейроттрансмиттеры и сенсорные нейромедиаторы [13]. Нарушение чувствительной иннервации роговой оболочки ведет к нарушению ее метаболизма и развитию дегенеративных изменений в эпителиоцитах, снижению митотической активности и как следствие - к нарушению целостности эпителия. Изменения в клетках переднего эпителия роговицы обусловлены в первую очередь важной ролью сенсорных медиаторов в патофизиологии эпителия, которые индуцируют пролиферацию, стимулируют миграцию эпителиоцитов, а также экспрессию интегринов [13,15, 23]

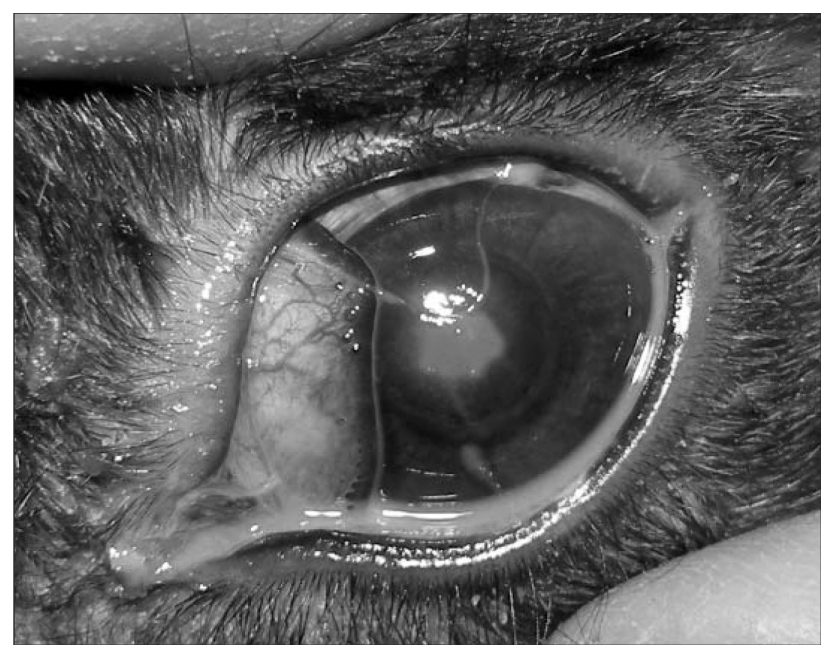

Рис. 2. Моделированный нейротрофический кератит, 14 сутки. Персистирующий дефект эпителия роговицы, с отеком и помутнением стромы, нитчатый кератит.

Следует отметить, что у всех животных на опытных глазах к пятым суткам эксперимента наблюдалось снижение слезопродукции с развитием нейротрофической эпителиопатии и вторичного синдрома сухого глаза. В развитии нарушений слезопродукции на разработанной модели нейротрофического кератита могут участвовать истощение компенсаторных механизмов рефлекторной регуляции слезопродукции, снижение чувствительности роговицы, нарушение нейрорефлекторного механизма слезоотделения, гипоксический стресс и др. [2].

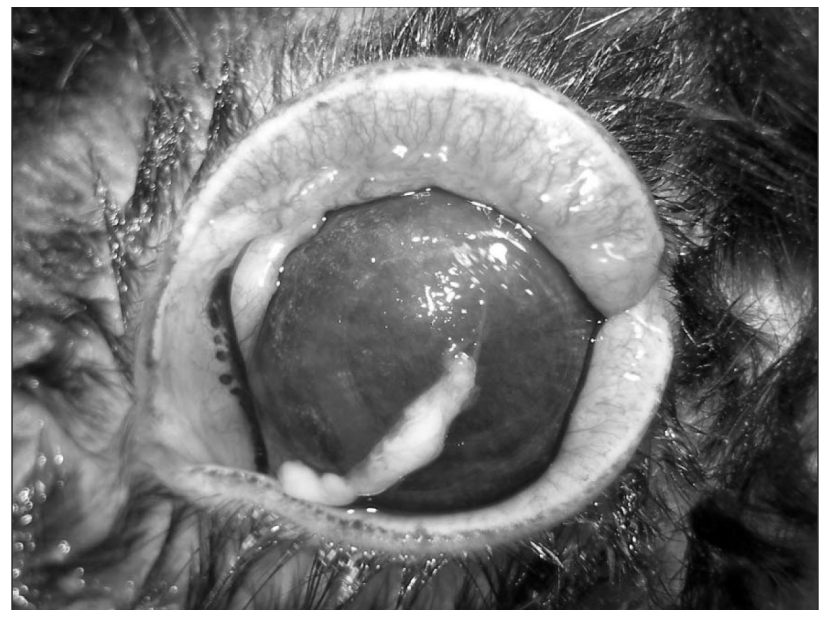

Рис. 3. Моделированный нейротрофический кератит, 29 сутки. Нитчатое слизистое отделяемое конъюнктивы. Отек и помутнение стромы роговицы, складки десцеметовой оболочки, снижение слезопродукции,

Полученные результаты свидетельствуют о том, что благодаря сочетанию факторов нарушения иннервации и питания зоны лимба (передавливание силиконовым циркляжем задних цилиарных артерий и нервов), формирования дефекта эпителия и передних слоев стромы роговицы в оптической зоне (нарушение целостности нервных волокон субэпителиального сплетения), торможения регенерации поверхности роговицы в результате инстилляций кортикостероидного препарата в конъюнктивальную полость развивался симптомокомплекс, соответствующий клиническим проявлениям I-II стадий нейротрофической кератопатииа по Mackie.

Заключение. В эксперименте in vivo разработана модель нейротрофического кератита (кератопатии), максимально приближенная к клиническим проявлениям благодаря сочетанию факторов, воздействующих на основные патогенетические звенья развития нейротрофического кератита с проявлением выраженных клинических стадий нейротрофического процесса в роговице.

\section{СПИСОК ЛИТЕРАТУРЫ}

1. Беляев В. С. Операции на роговой оболочке и склере / В. С. Беляев. - М.: Медицина, 1984. - 144 с.

2. Бржеский В. В., Сомов Е. Е. Роговично-конъюнктивальный ксероз (клиника, диагностика, лечение). - Изд. 2-е, част. Перераб. и доп. - СПб. - Изд. Левиша. - Санкт-Петербург. - 2003. - С.119.

3. Горгиладзе Т. У. Пересадка роговицы - Батуми.: Сабчота Аджара, 1983 - С.89-95. 
4. Вит В. В. Строение зрительной системы человека / В. В. Вит. - «Астропринт», 2003. - Одесса. - 655 с.

5. Дмитриев С. К. Оптимизация лечебной тактики при ожогах глаз на основе выяснения патогенетического значения изменений кровообращения в динамике ожогового процесса: Автореф. канд. диссерт. : 14.00.08 / Дмитриев Сергей Константинович. - Одесса, 1989. $-210 \mathrm{c}$.

6. Дрожжина Г. И., Иванова О. Н., Гайдамака Т. Б. Модель нейротрофического кератита. Патент Украины. Приоритетная справка № 201106827.

7. Дронов М. М. Руководство по кератопластике. Санкт-Петербург.: «Влазипресс», 1997. - С.115-117.

8. Каспарова Е. А. Лечение рецидивирующей эрозии роговицы // Вестник офтальмологии. - № 3. - 2009. C. $55-57$.

9. Макаров П. В. К хирургической тактике лечения тяжелой и особо тяжелой ожоговой травмы глаз (сообщение 2) // Вестн. офтальмол. - 2002. - № 4. C. $8-10$.

10. Матевосова Е. А., Луцевич Е. Е., Сафоно Т. Н. Современные методы лечения синдрома сухого глаза // Вестник офтальмол. - № 2. - 2009. - С.43-47.

11. Милюдин Е. С. Экспериментальная модель недостаточности региональных стволовых клеток роговичного эпителия // Вестник СамГУ - Естественнонаучная серия. - 2006. - № 9(49). - С.219-226.

12. Юмашева А. А. Динамика морфологических и биометрических изменений глаз при циркляже различными материалами. // Автореф. кандидатской диссертации - Одесса, 1979 г. - 178 с.

13. Bonini S., Rama P, Olzi1 D, Lambiase A. Neurotrophic keratitis // Eye. - 2003. - 17. - P.989-995.

14. Cavanagh H. D., Colley A. M. The molecular basis of neurotrophic keratitis // Acta Ophthalmol Suppl. - 1989. 192. - P.115-134.

15. Davis E. A., Dohlman C. H. Neurotrophic keratitis // Int. Ophthalmol Clin. - 2001. - 41. - P.1-11.
16. Ferrari G., Chauhan S. K., Ueno H., Nallasamy N., Gandolfi S., Borges L., Dana R. A novel mouse model for neurotrophic keratopathy: trigeminal nerve stereotactic electrolysis through the brain // Invest Ophthalmol Vis Sci. - 2011. - Apr 19;52(5). - P.2532-9.

17. Klyce S. D., Beuerman R. W. Structure and function of the cornea. In: Kaufman H. E., McDonald M. B., editors. The cornea, 2nd ed. Newton, MA: Butterworth-Heinemann 1997. - P.3-50.

18. Lambiase A., Rama P., Aloe L., Bonini S. Management of neurotrophic keratopathy // Curr Opin Ophthalmol. 1999. - 10. - P. 270-276.

19. Liesegang T. J. Ocular herpes simplex infection: pathogenesis and current therapy // Mayo Clin Proc. - 1988. 63. - P.1092-1105.

20. Mackie I. A. Neuroparalytic keratitis. In: Fraunfelder F., Roy F. H., Meyer S. M. (eds). Current Ocular Therapy. WB Saunders: Philadelphia, PA. - 1995. - P. 452-454.

21. Mackie I. A. Role of the corneal nerves in destructive disease of the cornea // Trans Ophthalmol Soc UK. 1978. - 93. - P.343.

22. Nakamura M., Kawahara M., Nakata K., Nishida T. Restoration of Corneal Epithelial Barrier Function and Wound Healing by Substance P and IGF-1 in Rats with Capsaicin-Induced Neurotrophic Keratopathy // Invest Ophthalmol Vis Sci. - 2003. - 44. - P.2937-2940.

23. Pushker N., Dada T., Vajpayee R. B. et al. Neurotrophic keratopathy // CLAO J. - 2001. - 27. - P.100-107.

24. Rosenwasser G. O., Holland S., Pflugfelder S. C. et al. Topical anesthetic abuse // Ophthalmology. — 1990. - 97. P.967-972.

25. Takashi Nagano et all. Effects of Substance P and IGF-1 in Corneal Epithelial Barrier Function and Wound Healing in a Rat Model of Neurotrophic Keratopathy // Invest Ophthalmol Vis Sci. - 2003. - 44. № 9. - P.3810-3815.

Поступила 18.10.2011 Рецензент канд. мед. наук В. Л. Осташевский

\section{MODEL OF NEUROTPOPHIC KERATITIS (KERATOPATHY). \\ Drozhzhyna G. I., Ivanova O. N., Gaydamaka T. B., Vit V. V. \\ Odessa, Ukraine}

Aim. To work out the experimental model of neurotrophic keratopathy maximally approaching the clinical manifestation of the disease.

The experimental investigation was performed in 10 rabbits (20 eyes). The new model of neurotrophic keratopathy includes combination of several factors: worsening of innervation and nutrition of the limbal zone (silicone circlage), corneal defect (central stromectomy of the cornea), inhibition of regeneration (corticosteroids installations). 